\title{
Decline of the Black Sea oxygen inventory
}

\author{
Arthur Capet $^{1,2}$, Emil V. Stanev ${ }^{3}$, Jean-Marie Beckers ${ }^{4}$, James W. Murray ${ }^{5}$, and Marilaure Grégoire ${ }^{2}$ \\ ${ }^{1}$ OGS, National Institute of Oceanography and Experimental Geophysics, Trieste, Italy \\ ${ }^{2}$ MAST, MARE, University of Liège, Liège, Belgium \\ ${ }^{3} \mathrm{HZG}$, Helmholtz-Zentrum Geesthacht, Hamburg, Germany \\ ${ }^{4}$ GHER, GeoHydrodynamics and Environment Research, University of Liège, Liège, Belgium \\ ${ }^{5}$ School of Oceanography, University of Washington, Seattle, WA, USA
}

Correspondence to: Arthur Capet (arthurcapet@gmail.com)

Received: 31 August 2015 - Published in Biogeosciences Discuss.: 2 October 2015

Revised: 17 February 2016 - Accepted: 19 February 2016 - Published: 1 March 2016

\begin{abstract}
We show that from 1955 to 2015, the inventory of oxygen in the Black Sea has decreased by $44 \%$ and the basin-averaged oxygen penetration depth has decreased from $140 \mathrm{~m}$ in 1955 to $90 \mathrm{~m}$ in 2015 , which is the shallowest annual value recorded during that period.
\end{abstract}

The oxygenated Black Sea surface layer separates the world's largest reservoir of toxic hydrogen sulfide from the atmosphere. The threat of chemocline excursion events led to hot debates in the past decades arguing on the vertical stability of the Black Sea oxic/suboxic interface. In the 1970s and 1980s, when the Black Sea faced severe eutrophication, enhanced respiration rates reduced the thickness of the oxygenated layer. Re-increasing oxygen inventory in 19851995 supported arguments in favor of the stability of the oxic layer. Concomitant with a reduction of nutrient loads, it also supported the perception of a Black Sea recovering from eutrophication. More recently, atmospheric warming was shown to reduce the ventilation of the lower oxic layer by lowering cold intermediate layer (CIL) formation rates.

The debate on the vertical migration of the oxic interface also addressed the natural spatial variability affecting Black Sea properties when expressed in terms of depth. Here we show that using isopycnal coordinates does not overcome the significant spatial variability of oxygen penetration depth. By considering this spatial variability, the analysis of a composite historical set of oxygen profiles evidenced a significant shoaling of the oxic layer, and showed that the transient "recovery" of the 1990s was mainly a result of increased CIL formation rates during that period.

As both atmospheric warming and eutrophication are expected to increase in the near future, monitoring the dynam- ics of the Black Sea oxic layer is urgently required to assess the threat of further shoaling.

\section{Introduction}

The Black Sea deep waters constitutes the world's largest reservoir of toxic hydrogen sulfide. $100 \mathrm{~m}$ of ventilated surface waters are all that separate this reservoir from the atmosphere. This situation results from the permanent halocline (Öszoy and Ünlüata, 1997) that separates the surface layer (of low salinity due to river inflow) from the deeper layer (of high salinity due to inflowing Mediterranean seawater), restraining ventilation to the upper layer (Fig. 1).

In the lower part of the halocline, a permanent suboxic layer separates the Black Sea surface oxygenated waters $\left(\left[\mathrm{O}_{2}\right]>20 \mu \mathrm{M}\right)$ from the deep sulfidic waters $\left(\left[\mathrm{H}_{2} \mathrm{~S}\right]>20 \mu \mathrm{M}\right)$ (Murray et al., 1989, 1995; Tugrul et al., 1992). More precisely, Murray et al. (1989) considered a threshold of $10 \mu \mathrm{M}$ of oxygen because they analyzed highquality oxygen data. The threshold of $20 \mu \mathrm{M}$ of oxygen was applied later to analyze historical oxygen data of lower quality. The upper $\left(\mathrm{O}_{2}\right.$ disappearance $)$ and lower $\left(\mathrm{H}_{2} \mathrm{~S}\right.$ onset $)$ interfaces of this suboxic layer are controlled by different biogeochemical and physical processes (Konovalov et al., 2006; Stanev et al., 2014), and undergo uncorrelated vertical migrations (Konovalov and Murray, 2001). Sinking organic matter is mainly respirated aerobically within the oxycline: the lower part of the oxygenated layer where oxygen concentration decreases downwards to $20 \mu \mathrm{M}$. Increasing flux of organic matter, induced by a period of high nutrient load from 


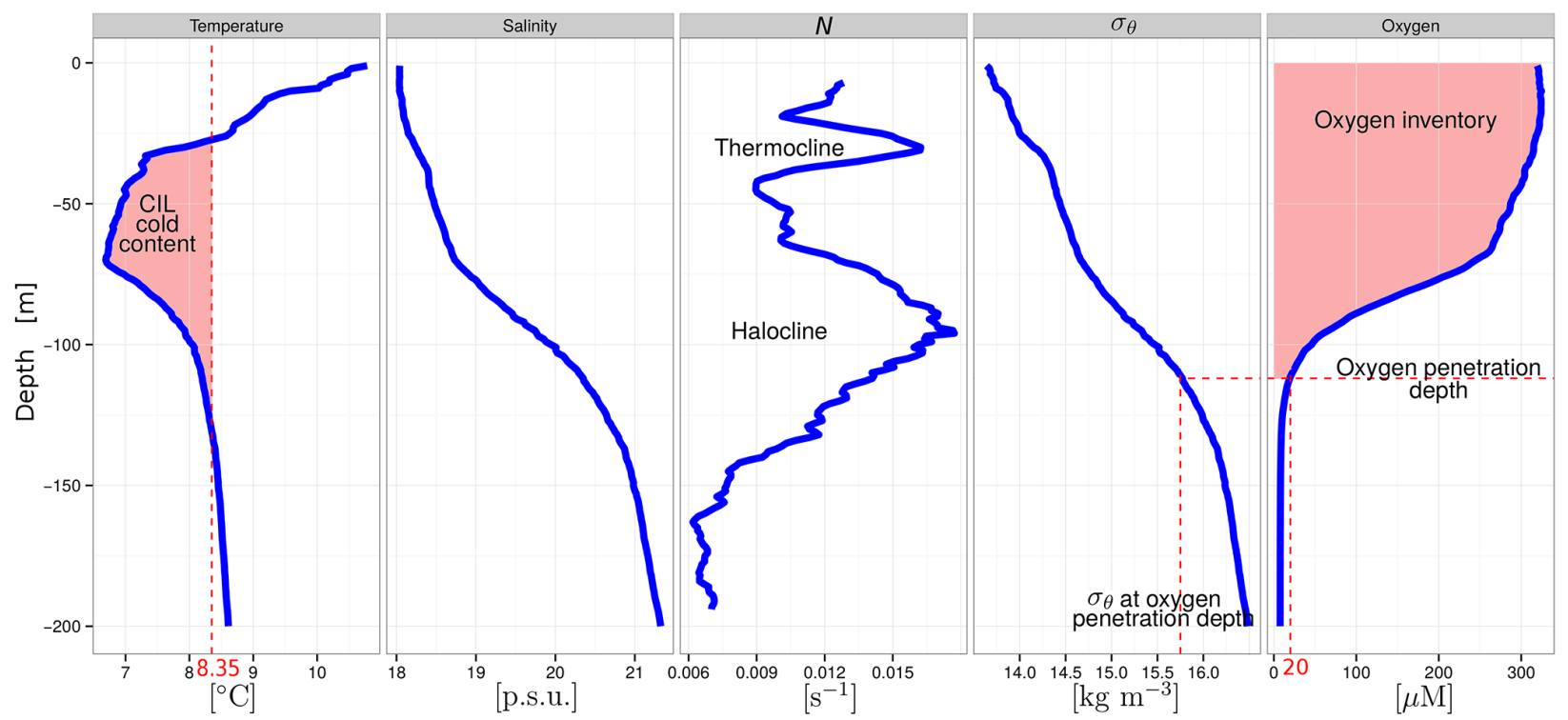

Figure 1. Typical profiles of temperature, salinity, Brunt-Väisälä frequency $(N)$, potential density anomaly $\left(\sigma_{\theta}\right)$ and oxygen concentration in the central Black Sea (May). Note the two peaks in the vertical stratification: the thermocline, which is seasonal and corresponds roughly to the upper limit of the cold intermediate layer and the halocline, which is permanent, and correspond roughly to the lower limit of the cold intermediate layer and the upper boundary of the suboxic zone. Red dotted lines and shaded areas illustrate the diagnostic values derived from each profile (Sect. 2.2).

the 1970 s to the late 1880 s, resulted in higher oxygen consumption above the suboxic layer and a shoaling of the upper suboxic interface (Codispoti et al., 1991; Konovalov and Murray, 2001; Tugrul et al., 2014).

After reduction of nutrient inputs around 1990 (Kroiss et al., 2006), the Black Sea was described as a recovering ecosystem (Mee et al., 2005; Oguz et al., 2006). This perspective was supported by improved eutrophication indices in the open sea (Kideys, 2002) as well as the stabilization of the upper suboxic interface in the 1990s (Konovalov and Murray, 2001). However, the timescale of the expected recovery (i.e., the timescale associated with the chain of biogeochemical mechanisms relating oxycline penetration depth to riverine nutrient loads) is not quantitatively understood. Several processes cause the oxycline depth to respond with a time lag to the reduction of riverine nutrient inputs. First, nutrients are mainly delivered to the northwestern shelf, where the accumulation of organic matter in the sediments buffers the riverine inputs, with slow diagenetic processes controlling and delaying the nutrient outflow across the seaward boundary (Capet et al., 2013). Second, the intermediate oxidation-reduction cycling of nitrogen, sulfur, manganese, iron and phosphorus that separates oxygen from hydrogen sulfide (Shaffer, 1986; Codispoti et al., 1991; Konovalov et al., 2006; Yakushev et al., 2007) can delay the response of the lower suboxic interface to changing nutrient fluxes by several years (Konovalov et al., 2006).

In addition to these biogeochemical factors, the dynamics of the upper and lower interfaces of the suboxic layer are controlled by physical processes (Konovalov et al., 2006; Stanev et al., 2014). In the Black Sea, dense waters formed by winter cooling and mixing (Staneva and Stanev, 2002) do not sink to the deepest layer, as in the Mediterranean Sea, but accumulate on top of the permanent halocline (Fig. 1). The resulting cold intermediate layer (CIL) is a major feature of the Black Sea vertical structure. Cold intermediate water formation and advection by the cyclonic basin-wide Rim Current (Öszoy and Ünlüata, 1997; Capet et al., 2012) ventilate the oxycline and thereby influence variability in the depth of the upper suboxic interface (Konovalov et al., 2006). Recently, atmospheric warming (Oguz et al., 2006) was shown to reduce the ventilation of the lower oxic layer (Tugrul et al., 2014; Pakhomova et al., 2014). At deeper levels, the dense sinking plume formed by the Mediterranean inflow through the Bosporus, which entrains water from the overlying CIL, injects fingers of oxygenated water directly into the deeper part of the suboxic layer and upper sulfidic layer and thus acts to control the depth of the lower suboxic interface (Konovalov and Murray, 2001; Konovalov et al., 2003, 2006; Glazer et al., 2006).

Previous long-term analyses of the vertical migration of the suboxic interfaces either ended (1955-1995; Konovalov and Murray, 2001) or started (1985-2015; Pakhomova et al., 2014) with the eutrophication period, excluding the largescale overview required to grasp the interactions of eutrophication and climate factors. Those analyses lacked a comprehensive consideration of the natural spatial and seasonal variability of the vertical distribution of oxygen. 


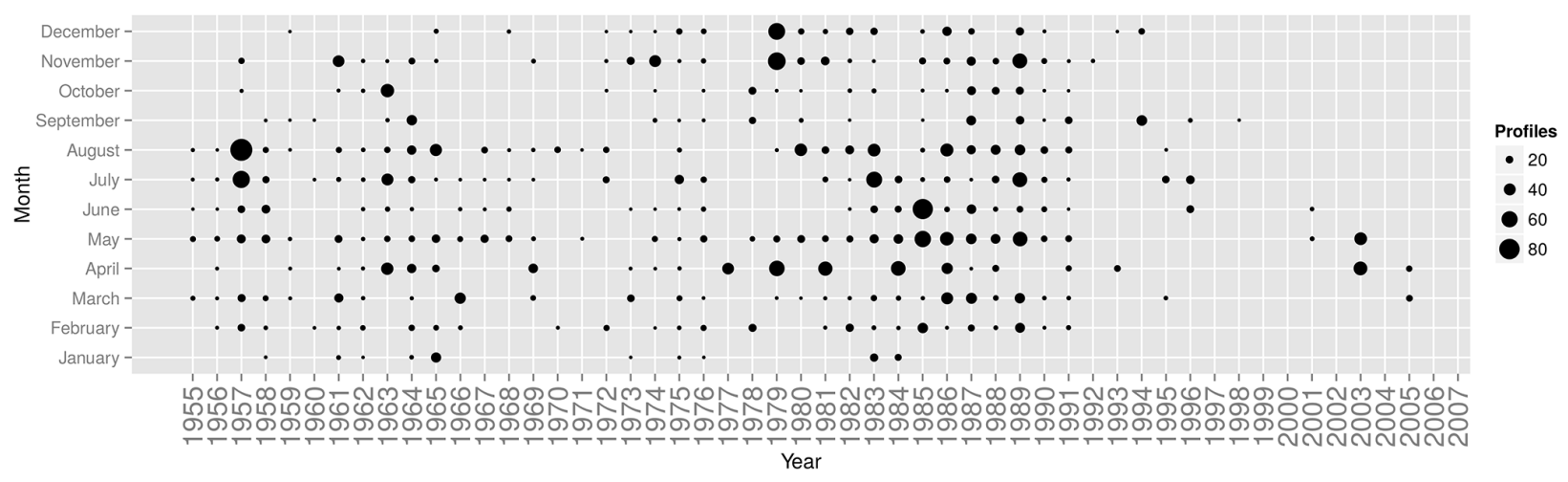

Figure 2. Temporal distribution of the ship-based oxygen profiles merged from the World Ocean Database, R/V Knorr 2003 and R/V Endeavor 2005 campaigns. Only the profiles containing at least five observation depths, one observation above $30 \mathrm{~m}$ depth and one record with $\left[\mathrm{O}_{2}\right]<20 \mu \mathrm{M}$ were considered.

In the presence of large gradients, uneven data distribution may induce artificial signals when interannual trends are assessed from direct annual averages. In the stratified Black Sea, properties expressed in terms of depth coordinates $(\mathrm{m})$ present a high spatial variability due to mesoscale features (Kempe et al., 1990) and to the general curvature of Black Sea isopycnals (Öszoy and Ünlüata, 1997; Stanev et al., 2014). As an alternative, using density (isopycnal levels, $\left.\sigma_{\theta}\right)$ as vertical coordinate is generally considered a stable solution to assess the vertical migration of the chemocline on a decadal scale (Tugrul et al., 1992; Saydam et al., 1993; Murray et al., 1995). However, the spatial confinement of the lateral oxygen injections associated with the Bosporus plume, as well as the spatial variability of diapycnal ventilating processes (Zatsepin et al., 2007), imposes a horizontal structure to the oxygen penetration depth when expressed in terms of density (Stanev et al., 2004; Glazer et al., 2006). As this spatial gradient might scale with the temporal variations (a range of $0.17 \mathrm{~kg} \mathrm{~m}^{-3}$ was observed during the Knorr 2003 campaign, Glazer et al., 2006), it has to be considered when deriving interannual trends.

The present study describes the application of the DIVA (Data-Interpolating Variational Analysis) detrending procedure (Troupin et al., 2012; Capet et al., 2014) to untangle the temporal and spatial variability of three indices related to the Black Sea oxygenation status: the depth and density level of oxygen penetration and the oxygen inventory. These values were diagnosed from a composite historical data set of oxygen vertical profiles. We review the evolution of those indices through the past 60 years and discuss the respective controls of eutrophication and climate factors.

\section{Material and methods}

\subsection{Data}

We gathered a composite set of 4385 ship-based vertical profiles (oxygen, temperature and salinity) obtained between 1955 and 2005 in the Black Sea using CTD rosette bottles, continuous pumping profilers (Codispoti et al., 1991) and in situ analyzers (Glazer et al., 2006) from the World Ocean Database (http://www.nodc.noaa.gov/OC5/SELECT/ dbsearch/dbsearch.html), and R/V Knorr 2003 and R/V Endeavor 2005 campaigns (http://www.ocean.washington. edu/cruises/Knorr2003/, http://www.ocean.washington.edu/ cruises/Endeavor2005/). Only the profiles containing at least five observation depths, one observation above $30 \mathrm{~m}$ depth and one record with $\left[\mathrm{O}_{2}\right]<20 \mu \mathrm{M}$ were retained for analysis. The temporal and spatial distribution of the selected shipbased profiles are displayed in Figs. 2 and 3, respectively.

To complement the analysis of ship-based casts, we considered profiles originating from 10 Argo autonomous profilers (May 2010-December 2015). Only good quality-checked real-time data were considered (Carval et al., 2014). Two of these floats (Argo ID 7900465 and 7900466) have been presented and discussed by Stanev et al. (2013), where the consistence and comparability of Argo and historical profiles is asserted within a $1 \mu \mathrm{M}$ error range.

Several studies address the error of Argo real-time oxygen data (e.g., Bittig and Körtzinger, 2015; Takeshita et al., 2013; Johnson et al., 2015). Demonstrating that the Black Sea real-time Argo data are precisely (i.e., at fine scales) comparable with historical Winkler data, or identifying the relevant correction, is beyond the scope of the present study which addresses monthly to decadal timescales. Evenly distributed small-scale error (e.g., difference between ascending and descending profiles due to sensor time response) were thus filtered by the temporal smoothing. However, a systematic error is not strictly excluded which could reach an under- 


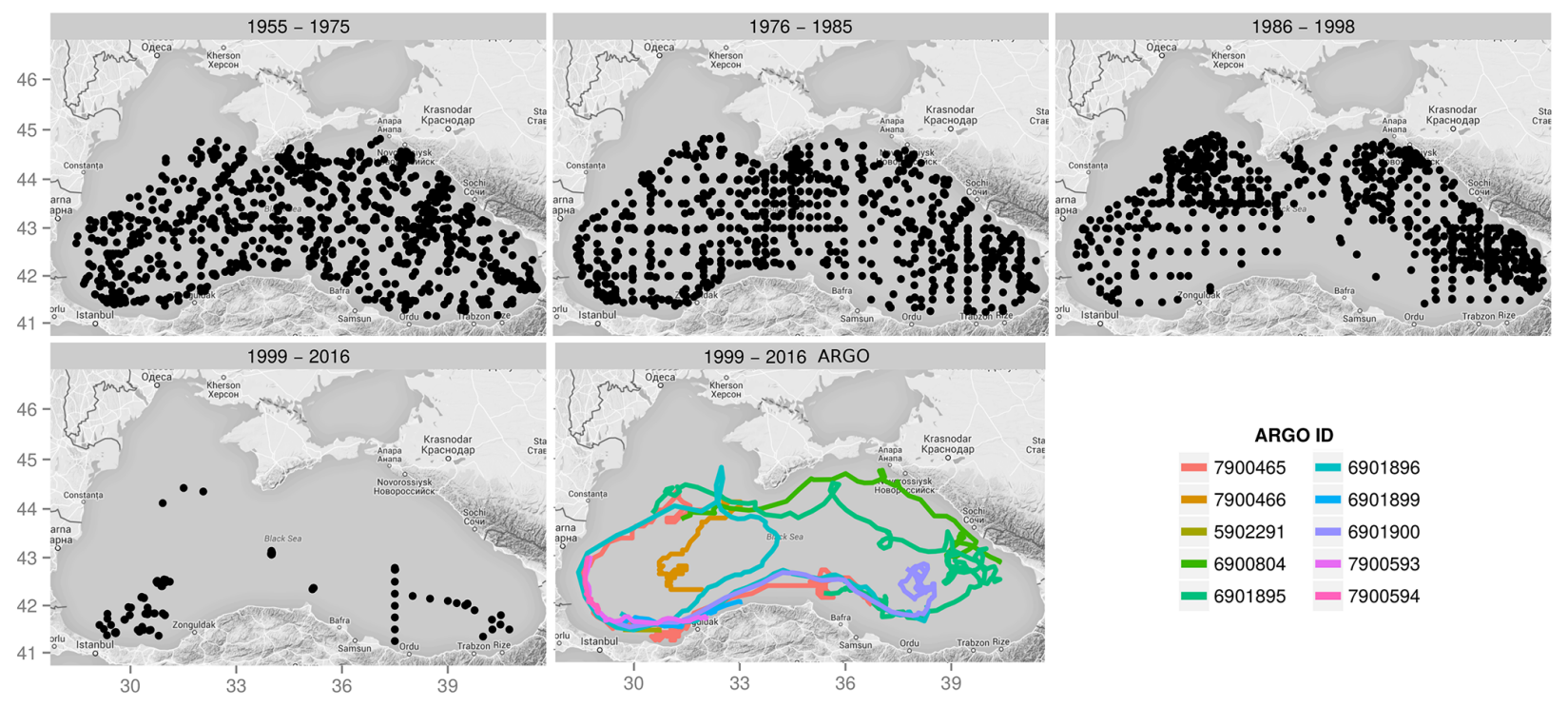

Figure 3. Distribution of the ship-based oxygen profiles (Fig. 2) available for each period (black dots). The last panel displays the trajectories of the ARGO floats. Number of profiles for each period are given in the text. Map data: ${ }^{\circledR}$ Google 2015.

estimation of $10 \mu \mathrm{M}$ (Virginie Thierry, IFREMER, personal communication, January 2016). Therefore, we evaluated a "worst-case" scenario in the analysis of Argo data by considering a systematic underestimation of oxygen concentration by $10 \mu \mathrm{M}$.

Although most of the floats drifted along the basin periphery, some were also advected in the central part (Fig. 3). These trajectories highlight the range of spatial variability for the diagnostics described in Sect. 2.2.

The investigation time frame was divided into periods according to data availability and to dissociate known phases of eutrophication (Oguz, 2008; Kroiss et al., 2006) and CIL dynamics (Piotukh et al., 2011; Capet et al., 2014) - see also Oguz et al. (2006) for decadal cycles in the Black Sea: 19551975 (1575 ship-based profiles), 1976-1985 (1350 shipbased profiles), 1986-1998 (1324 ship-based profiles) and 1999-2015 (136 ship-based profiles and 1393 Argo profiles).

\subsection{Profile analysis}

From each profile we derived (1) the depth and (2) the potential density anomaly $\sigma_{\theta}$ where oxygen concentration went below $20 \mu \mathrm{M}$ and (3) the oxygen inventory, integrated above this limit (Fig. 1). The threshold value of $20 \mu \mathrm{M}$ used to define the upper interface of the suboxic layer was suggested to compare oxygen observations issued from sensors with different detection limits (Konovalov and Murray, 2001). To evaluate how a $10 \mu \mathrm{M}$ underestimation by Argo profilers would affect the main conclusions, oxygen penetration depths an density levels for Argo were also computed using a threshold of $10 \mu \mathrm{M}$.

The CIL cold content (Fig. 1) was diagnosed from corresponding salinity and temperature profiles following Capet et al. (2014). It indicates on the intensity of CIL formation smoothed over 4-5 years, i.e,. the residence time of cold intermediate waters (Staneva and Stanev, 2002; Piotukh et al., 2011; Capet et al., 2014):

CIL cold content $=c \rho \int_{\mathrm{CIL}}\left[T(z)-T_{\mathrm{CIL}}\right] \mathrm{d} z$,

where $\rho$ is the density and $c$ the heat capacity and $T_{\mathrm{CIL}}=$ $8.35^{\circ} \mathrm{C}$ (Stanev et al., 2013).

\subsection{DIVA analysis}

Climatologies for the whole period and interannual trends were identified for the three oxygen diagnostics by applying the DIVA detrending algorithm on the ship-based data set (see details in Appendix A).

In short, the DIVA interpolation software (http://modb. oce.ulg.ac.be/mediawiki/index.php/DIVA; Troupin et al., 2012) computes a gridded climatology obtained by minimizing a cost function which penalizes gradients and misfits with observations. The DIVA detrending algorithm (Capet et al., 2014) computes trends for each year, i.e., the average difference between data pertaining to this year and the spatial analysis at these data locations. This procedure allows one to account for the sampling error associated with spatial/temporal variability. 

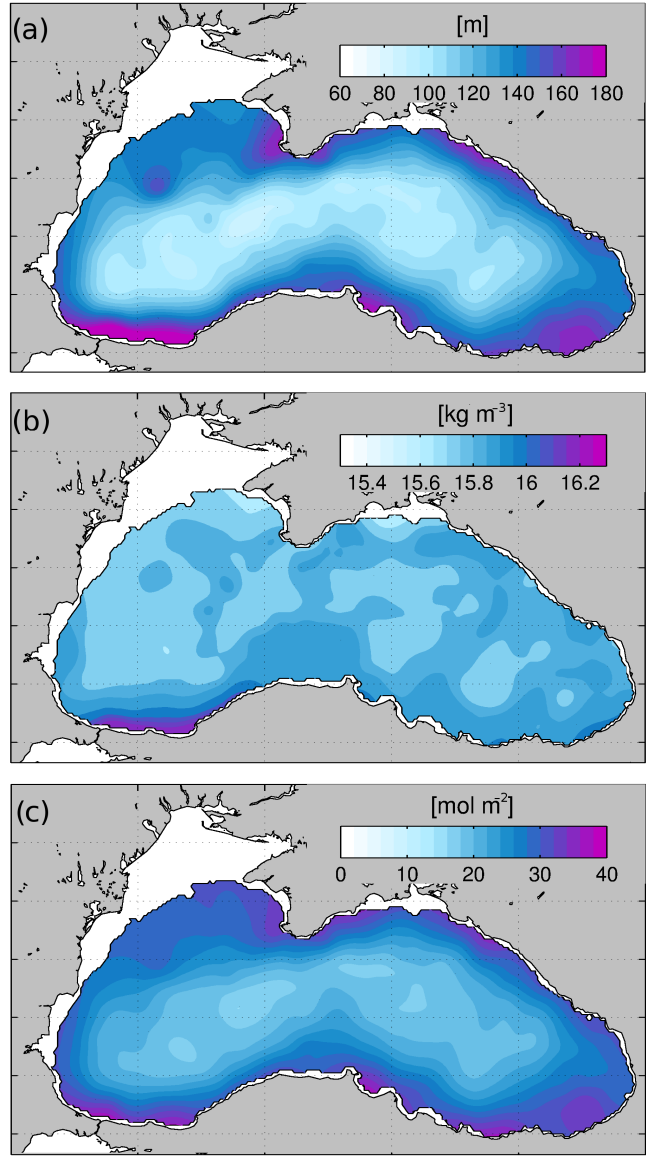

Figure 4. Annual climatologies of (a) oxygen penetration depth (where $\left[\mathrm{O}_{2}\right]=20 \mu \mathrm{M}$ ), (b) potential anomaly at oxygen penetration depth and (c) oxygen inventory. These spatial climatologies were constructed from the ship-based data set (1955-2005), accounting for the temporal variability of these diagnostics and the uneven distribution of data (see Sect. 2.3).

\section{Results}

\subsection{Spatial variability}

The spatial distribution of the oxygen penetration depth (Fig. 4a) reflects the general curvature of the Black Sea vertical structure. A range of approximately $70 \mathrm{~m}$ was observed between oxygen penetration depth in the periphery $(150 \mathrm{~m})$ and in the central part $(80 \mathrm{~m})$.

A significant spatial variability remains when expressing oxygen penetration in terms of potential density anomaly $\sigma_{\theta}$ (Fig. 4b). While the central part bears typical values of $15.75 \mathrm{~kg} \mathrm{~m}^{-3}$, a deeper anomaly (in terms of density) can be seen in the area of the Bosporus plume $\left(16.1 \mathrm{~kg} \mathrm{~m}^{-3}\right)$, which then decreases along the southern $\left(15.85-15.9 \mathrm{~kg} \mathrm{~m}^{-3}\right)$ and eastern periphery $\left(15.85 \mathrm{~kg} \mathrm{~m}^{-3}\right)$. These result in a range of spatial variability of $0.35 \mathrm{~kg} \mathrm{~m}^{-3}$.

The spatial distribution of the oxygen inventory (Fig. 4c) follows that of the oxygen penetration depth. The range of spatial variability reaches $12 \mathrm{molO} \mathrm{m}^{-2}$, i.e., between $17 \mathrm{molO} \mathrm{m}^{-2}$ in the central part and $29 \mathrm{molO} \mathrm{m}^{-2}$ in the periphery.

The ranges of spatial variability derived from these spatial analyses agreed with those depicted by the Argo profilers (Fig. 5), bearing in mind the different timescales under consideration.

\subsection{Temporal variability}

Between 1955 and 2005, the oxygen penetration depth rose by an average rate of $7.9 \mathrm{~m}$ per decade (Fig. 6a). The basin average was of $140 \mathrm{~m}$ in 1955 (ship-based), $100 \mathrm{~m}$ in 2005 (ship-based) and $90 \mathrm{~m}$ in 2015 (Argo). Considering a systematic underestimation by $10 \mu \mathrm{M}$ in the Argo data would result in an oxygen penetration depth around $95 \mathrm{~m}$ for 2015 (Argo).

This shoaling was also observed on the potential density scale $\left(-0.074 \mathrm{~kg} \mathrm{~m}^{-3}\right.$ per decade, Fig. $\left.6 \mathrm{~b}\right)$. The basin average was of $16.05 \mathrm{~kg} \mathrm{~m}^{-3}$ in 1955 (ship-based), $15.6 \mathrm{~kg} \mathrm{~m}^{-3}$ in 2005 (ship-based) and around $15.3 \mathrm{~kg} \mathrm{~m}^{-3}$ in 2015 (Argo). Considering a systematic underestimation by $10 \mu \mathrm{M}$ in the Argo data would result in values of $15.5 \mathrm{~m}$ for 2015 (Argo).

The oxygen inventory, integrated from the surface down to the suboxic upper interface, decreased by $44 \%$ during the last 60 years (Fig. 6c), considering the ship-based estimate for $1955\left(27 \mathrm{~mol} \mathrm{Om}^{-2}\right)$ and the Argo estimate for $2015\left(15 \mathrm{~mol} \mathrm{O} \mathrm{m}^{-2}\right)$. The few ship-based profiles available after the mid-1990s revealed the lowest oxygen inventories recorded during the time frame covered by the present study.

The temporal signals departed from these linear trends between 1988 and 1996, during which deeper oxygen penetration (both in terms of depth and density) and higher oxygen content were observed.

\subsection{Oxygen inventory and CIL cold content}

Positive relationships between oxygen inventory and CIL cold content were obtained for all periods (Fig. 7). Considering a given level of CIL cold content, the corresponding oxygen inventory decreased significantly from period 1955 1975 to period 1986-1998 (Fig. 7b).

The relationship between oxygen inventory and CIL cold content for the period 1999-2015 does not differ significantly from that obtained for the period 1986-1998 (Fig. 7b). This comparison should be considered with caution, however, as oxygen profiles for the period 1999-2015 originate mainly from Argo floats whose sampling rate is much higher than ship-based casts.

High CIL cold content is much more frequent during the period 1986-1998, while low CIL cold content is more frequent during 1999-2013. 

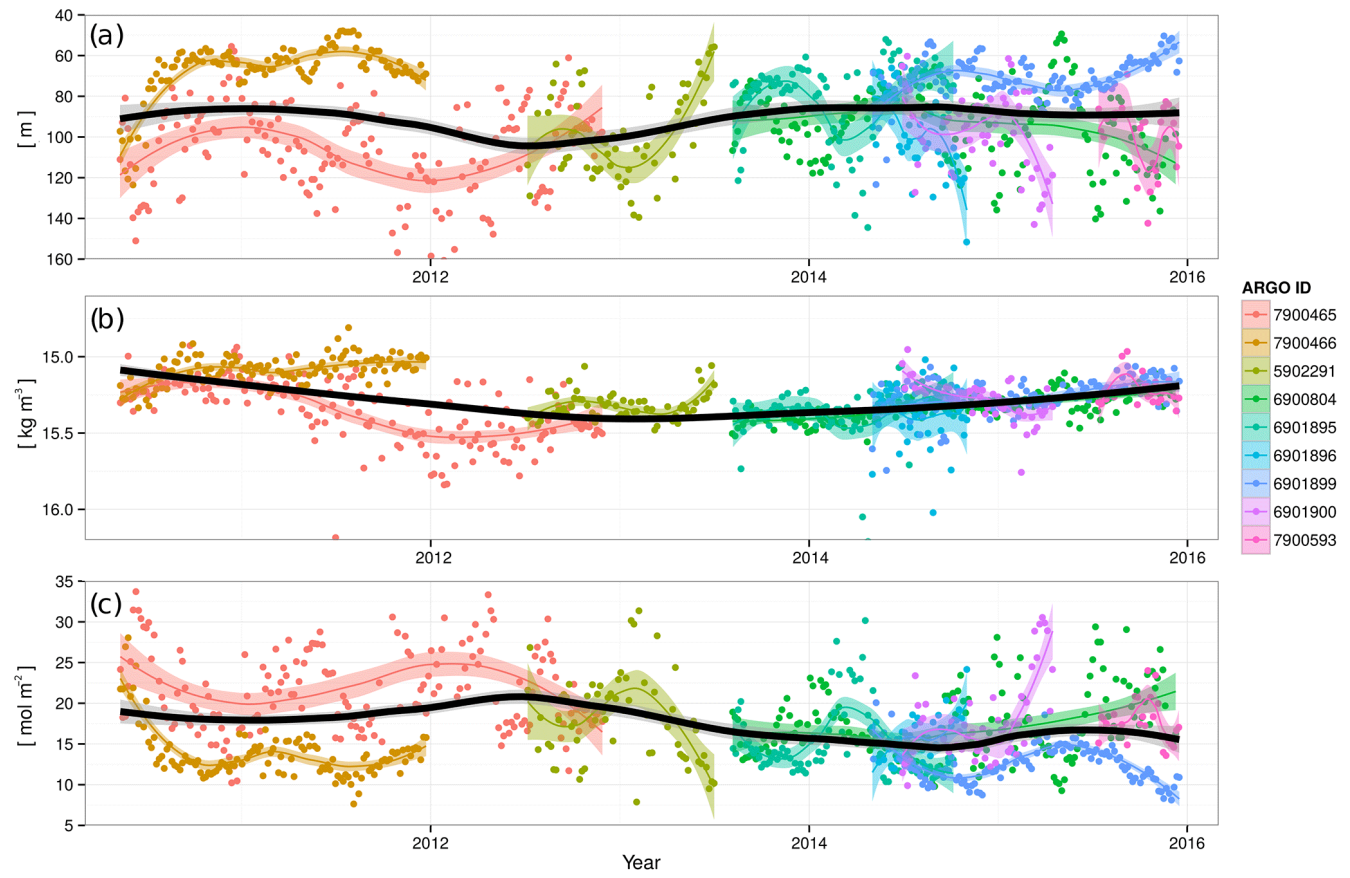

Figure 5. (a) Oxygen penetration depth, (b) oxygen penetration density levels and (c) oxygen inventory derived from Argo profiles. The color legend gives the unique Argo identification number of the floats. Colored lines and color-filled areas indicate smoothed time series for each float (second-degree LOESS smoother, $\operatorname{span}=0.5,0.95$ confidence intervals). The black line and gray shaded area are the smoothed time series obtained when considering all floats (reported in Fig. 6).

\section{Discussion}

The spatial analysis of oxygen penetration depth showed that the use of density coordinates does not eliminate the sampling error associated with uneven spatial coverage (Fig. 4). Deeper oxygen penetration (on a density scale) in the Bosporus area were expected, in relation with the intermediate lateral injections associated with the Bosporus plume. In addition, deeper oxygen penetration (on a density scale) in the southern and eastern periphery suggests the occurrence of diapycnal ventilation along the steep bathymetry (Zatsepin et al., 2007). The aggregation of the most recent ship-based profiles in the Bosporus area and in the southeastern region (Fig. 3), might have led to an overestimation of the basinaverage oxygen penetration depth in the last decade, hence to an underestimation of the shoaling trend of the Black Sea oxic layer.

Considering spatial variability revealed a clear shoaling trend for oxygen penetration depth. This shoaling can be seen on both depth and density scales (Fig. 6a, b). This confirms the hypothesis that the shoaling of oxygen penetration depth is not due to a general shoaling of the main halocline, but is associated with a shifted biogeochemical balance in the oxygen budget (Codispoti et al., 1991; Konovalov and Murray, 2001; Tugrul et al., 2014).

Using $\sigma_{\theta}$ coordinates depicts clearer temporal variations (Figs. 5 and 6). The shoaling rate varies in time and was more intense during 1970-1985 and from 1996 onwards. Argo diagnostics using different oxygen threshold show a larger discrepancy in the case of pycnal coordinates. The cooccurrence of density and oxygen gradients (Fig. 1) results in a higher sensitivity to the sensor accuracy for the $\sigma_{\theta}$ diagnostic for oxygen penetration. However, even a systematic underestimation by $10 \mu \mathrm{M}$ of oxygen concentration by Argo profilers does not invalidate our results.

The positive correlations between CIL cold content and oxygen inventory observed for all the periods illustrate the ventilation of intermediate layers by CIL formation and advection (Fig. 7b). In the early 1990s, the transient recovery of the three oxygenation diagnostics (Figs. 6a, b, c, 7a) provided arguments supporting the stability of the oxic interface (Tugrul et al., 1992; Buesseler et al., 1994). This stabilization matched the convenient perception of a general recovery of the Black Sea ecosystem after the reduction of nutrient load around 1990 (Kroiss et al., 2006). However, Fig. 7 indicates that the oxygenation diagnostics obtained for the period 1986-1998 were associated with much higher ventilation rates (i.e., higher CIL cold content) than during the previous periods. If, in response to nutrient reduction, the biogeochemical oxygen consumption terms had been lower during the period 1986-1998 than previously, the increased ventilation during that period would have resulted in higher oxygen inventories. Instead, oxygen inventories observed during 1986-1998 are lower than those observed in the previous 

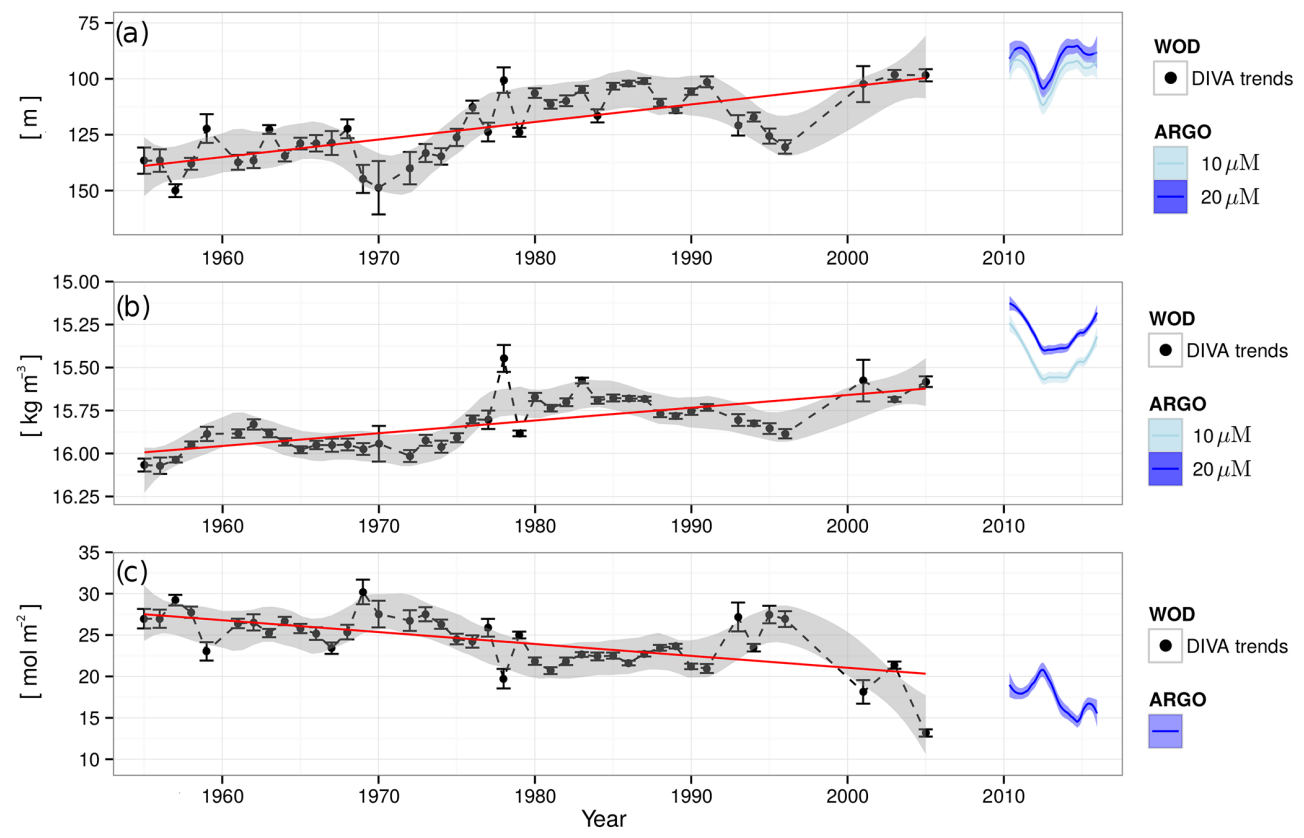

Figure 6. Trends of (a) oxygen penetration depth, (b) oxygen penetration density level $\left(\sigma_{\theta}\right)$ and (c) oxygen inventory deduced from (dots) DIVA analysis of ship-based casts and (blue) ARGO floats. In (a) and (b), the diagnostics from ARGO are also shown for the lower threshold of $10 \mu \mathrm{M}$ to acknowledge a potential bias between Winkler and Argo data. Red lines: the linear trends assessed from the ship-based data set are $-7.9 \mathrm{~m} \mathrm{decades}^{-1},-0.074 \mathrm{~kg} \mathrm{~m}^{-3}$ decades $^{-1}$ and $-1.44 \mathrm{~mol} \mathrm{O} \mathrm{m}^{-2}$ decades $^{-1}$ for (a), (b) and (c), respectively. Error bars on DIVA estimated trends indicate the standard error associated with the estimation of the mean misfit for each year (see Appendix A).

decade for similar levels of CIL cold content. We conclude that high CIL formation rates during this period (Piotukh et al., 2011; Capet et al., 2014) provided enough ventilation to mask ongoing high oxygen consumption.

The fact that the relationship between oxygen inventories and CIL content for the last period 1999-2015 is similar to that of 1986-1998 indicates a stabilization in the biogeochemical oxygen consumption terms. Higher air temperature in this last period (Oguz and Cokacar, 2003; Oguz et al., 2006; Pakhomova et al., 2014), by limiting winter convective ventilation events (Capet et al., 2014) led to the lowest oxygen inventories ever recorded for the Black Sea (Fig. 6c).

Forecasted global warming, without excluding transient high ventilation periods, will limit CIL water formation (Capet et al., 2014) and reduce the oxygenation of the Black Sea intermediate layers. At the same time, uncertainties remain regarding the capacity of re-flourishing economies of the lower Danube watershed to recover their productivity in a more sustainable, less polluting form. Economic development in the Danube Basin could reverse the improving situation of eutrophication if nutrients are not managed properly (Kroiss et al., 2006). Under these conditions, there is no reason to expect that the oxycline shoaling observed over the past 60 years will stabilize.

There are reasons to worry about a rising oxycline in the Black Sea. First, biological activity is distributed vertically on the whole oxygenated layer, as indicated by zooplankton dial migration (Ostrovskii and Zatsepin, 2011). The reduction of the oxygenated volume described in this study could therefore have impacted on Black Sea living stocks by reducing carrying capacity and increasing predation encounter rates. It would be timely to estimate now the impact that a further shoaling of the oxic interfaces would bear on the Black Sea resources for the fishing industry.

Second, under present conditions, a massive atmospheric release of hydrogen sulfide caused by a sudden outcropping of anoxic waters remains unlikely, due to the stability of the Black Sea pycnal structure. Such outcropping event of sulfidic waters would have dramatic ecological and economical consequences (Mee, 1992). On 27 September 2005, an anomalous quasi-tropical cyclone was observed over the western Black Sea that led, in a few days, to the outcropping of waters initially located at $30 \mathrm{~m}$ depth (Efimov et al., 2008). Two years earlier, sulfide was measured in the same area (western central gyre) at around $80 \mathrm{~m}$ (Glazer et al., 2006). Because global warming is expected to increase the occurrence of extreme meteorological events (Beniston et al., 2007), every meter of oxycline shoaling would bring the Black Sea chemocline excursion events closer to the realm of possibility. 


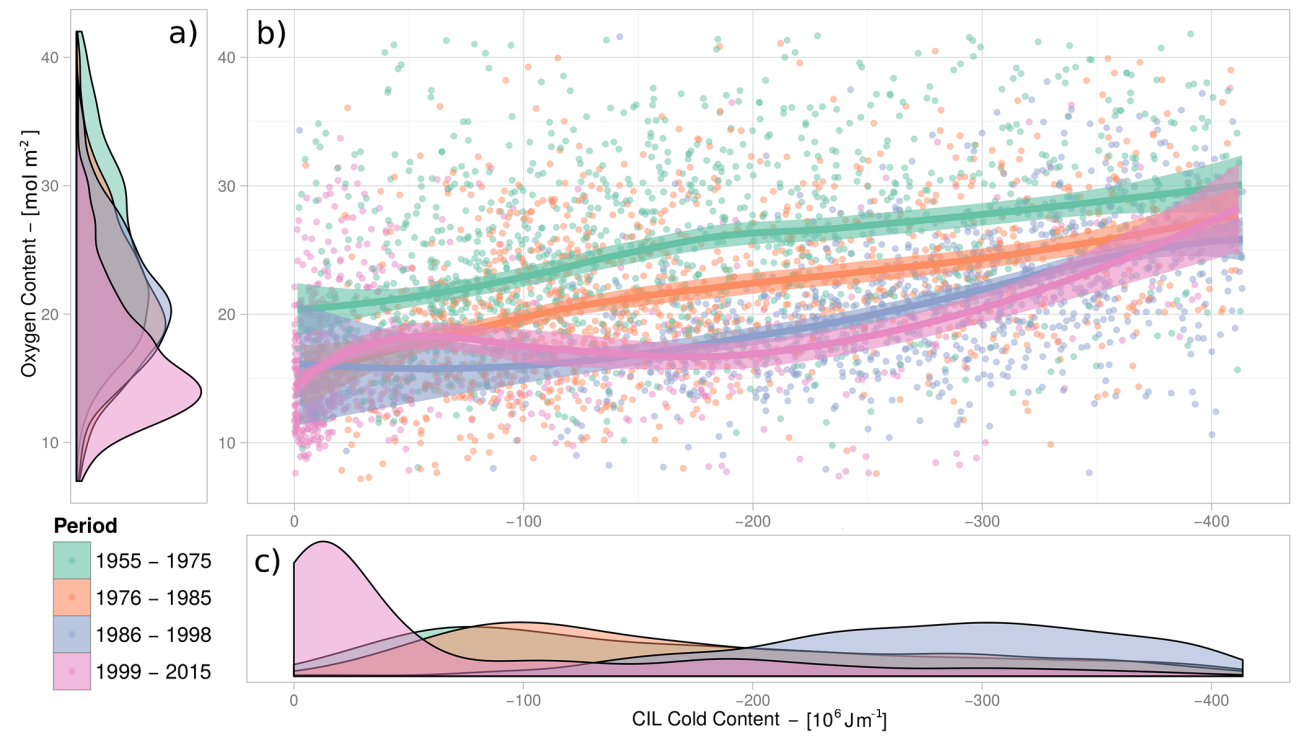

Figure 7. Impact of convective ventilation on oxygen inventory. Frequency distributions of (a) oxygen inventory and (c) cold intermediate layer (CIL) cold content diagnosed from ship-based and Argo profiles for different periods (color legend). (b) LOESS regressions (second degree polynomials, span $=0.75$, Cleveland et al., 1992) between oxygen inventory and CIL cold content for the different periods (confidence interval $\alpha=0.99)$. The positive relationships observed during each period illustrate the ventilating action of CIL formation as a source of oxygen to the intermediate levels. The shift of these relationships towards lower oxygen inventories indicates shift in the oxygen budgets (higher consumption) that are independent of the intensity of CIL formation.

\section{Conclusions}

The present study evidenced the decline of the Black Sea oxygen inventory during the second half of the 20th century and first decade of the 21st, and highlighted the threat that further atmospheric warming casts upon the vertical stability of the Black Sea oxygenated layer.

Further works are urgently required to assess how actual nutrient emission policies adequately prevent, in the context of forecasted warming, the ecological and economical damages that would arise from a further shoaling of the oxic interface.

Spatially resolved biogeochemical models are needed to integrate explicitly the interacting processes affecting the Black Sea oxycline.
It is also essential (1) to determine to which extent the shoaling of the oxygen penetration depth entrains a shoaling of the sulfidic onset depth, (2) to set up a continuous monitoring of the Black Sea oxygen inventory and the intensity of winter convective ventilation (through CIL cold content), and (3) to clarify and quantify the interplay of diapycnal and isopycnal ventilation mechanisms and, in particular, the role played by the peripheral permanent/semipermanent mesoscale structures and how this relates to the intensity of the Rim Current (Stanev et al., 2014; Kubryakov and Stanichny, 2015). We propose that these objectives might be answered by maintaining in the Black Sea a minimum population of both moored and drifting autonomous profilers equipped with oxygen and sulfidic sensors. 


\section{Appendix A: The DIVA detrending algorithm}

DIVA (Data-Interpolating Variational Analysis) is a method for spatial interpolation. Its principle is to construct an analyzed field $\varphi$ that satisfies a set of constraints expressed in the form of a cost function over a spatial domain $\Omega$. The cost function is made up of (1) an observation constraint, which penalizes the misfit between data and analysis, and (2) a smoothness constraint, which penalizes the irregularity of the analyzed field (gradients, Laplacian, etc.).

Let us assume that we work with data anomalies, i.e., a reference (or background) field is subtracted from the data points prior the analysis. For $N$ data anomalies $d_{i}$ at locations $\left(x_{i}, y_{i}\right)$, the cost function reads, in Cartesian coordinates,

$$
\begin{aligned}
J[\varphi] & =\int_{\Omega}\left(\nabla \nabla \varphi: \nabla \nabla \varphi+\alpha_{1} \nabla \varphi \cdot \nabla \varphi+\alpha_{0} \varphi^{2}\right) \mathrm{d} \Omega \\
& +\sum_{i=1}^{N} \mu_{i}\left[d_{i}-\varphi\left(x_{i}, y_{i}\right)\right]^{2} \\
& =J_{\text {smooth }}[\varphi]+J_{\text {obs }}[\varphi],
\end{aligned}
$$

where $\mu_{i}, \alpha_{0}$ and $\alpha_{1}$ are coefficients related to characteristics of the data set. $\nabla$ is the horizontal gradient operator and $\nabla \nabla \varphi: \nabla \nabla \varphi=\sum_{i} \sum_{j}\left(\partial^{2} \varphi / \partial x_{i} \partial x_{j}\right)\left(\partial^{2} \varphi / \partial x_{i} \partial x_{j}\right)$, the generalization of the scalar product of two vectors.

The first term of Eq. (A1) measures the spatial variability (curvature, gradient and value) of the analyzed field and is identified as the smoothness constraint. The second term is a weighted sum of data-analysis misfits and is identified as the observation constraint: it tends to pull the analyzed field towards the observations. The coefficients of Eq. (A1) can be determined from (1) the relative weights $w_{i}$ attributed to each observation $d_{i}$, (2) the correlation length $L$ and (3) the signalto-noise ratio $\lambda$ (Troupin et al., 2012). The analyses presented in this study were achieved with equal weights $w_{i}=1, L=$ $0.8^{\circ}$ and $\lambda=0.5$. The minimization of Eq. (A1) is solved over $\Omega$ with a finite-element technique (Brasseur et al., 1996) which excludes data influence across land points (Troupin et al., 2010).
The detrending algorithm, presented in Capet et al. (2014) with synthetic and real case studies, proceeds as follows. Input data can be classified amongst the different classes $C_{j}$ (e.g., 1990, 1991, ...) of a given group $C$ (e.g., the year). The observation constraint of the functional Eq. (A1) can then be rewritten by including an unknown trend value for each class $\left(d_{C_{1}}, d_{C_{2}}, \ldots\right)$ :

$$
\begin{aligned}
J_{\mathrm{obs}}[\varphi] & =\sum_{i \in C_{1}} \mu_{i}\left[d_{i}-d_{C_{1}}-\varphi\left(x_{i}, y_{i}\right)\right]^{2} \\
& +\sum_{i \in C_{2}} \mu_{i}\left[d_{i}-d_{C_{2}}-\varphi\left(x_{i}, y_{i}\right)\right]^{2}+\cdots
\end{aligned}
$$

If the function $\varphi(x, y)$ were known, minimization with respect to each of the unknowns $d_{C_{j}}$ would yield

$d_{C_{1}}=\frac{\sum_{i \in C_{1}} \mu_{i}\left[d_{i}-\varphi\left(x_{i}, y_{i}\right)\right]}{\sum_{i \in C_{1}} \mu_{i}}$

and similarly for the other classes: the trend for each class is the weighted misfit of the class with respect to the overall analysis.

Using an analysis without detrending as a first guess for $\varphi$, trends are computed for each classes in each group and subtracted from the original data. Following this, a new analysis is performed, the trends are recalculated, and the iterations continue until a specified convergence criterion is fulfilled. The procedure can be generalized with several groups of classes. The present study considered years and months.

The DIVA software and up-to-date related information can be found on http://modb.oce.ulg.ac.be/mediawiki/index.php/ DIVA. 
Acknowledgements. This study was achieved in the context of the PERSEUS project, funded by the EU under FP7 Theme "Oceans of Tomorrow" OCEAN.2011-3 Grant Agreement No. 287600. A. Capet is currently cofunded by the European Union under FP7-People-Co-funding of Regional, National and International Programmes, GA n. 600407 and the Italian Ministry of University and Research and National Research Council (Bandiera project RITMARE). E. V. Stanev acknowledges support from the EC project E-AIMS (grant 312642). Argo data were collected, checked and made freely available by the International Argo Program, part of the Global Ocean Observing System, and the national programs that contribute to it (http://www.argo.ucsd.edu, http://argo.jcommops.org). This is MARE publication number 323.

Edited by: L. Stramma

\section{References}

Beniston, M., Stephenson, D. B., Christensen, O. B., Ferro, C. A., Frei, C., Goyette, S., Halsnaes, K., Holt, T., Jylhä, K., Koffi, B., Palutikof, J., Schöll, R., Semmler, T., and Woth, K.: Future extreme events in European climate: an exploration of regional climate model projections, Climatic Change, 81, 71-95, 2007.

Bittig, H. C. and Körtzinger, A.: Tackling oxygen optode drift: Near-surface and in-air oxygen optode measurements on a float provide an accurate in-situ reference, J. Atmos. Ocean. Technol., 32, 1536-1543, 2015.

Brasseur, P., Beckers, J.-M., Brankart, J.-M., and Schoenauen, R.: Seasonal temperature and salinity fields in the Mediterranean Sea: Climatological analyses of a historical data set, Deep-Sea Res. Pt. I, 43, 159-192, doi:10.1016/0967-0637(96)00012-X, 1996.

Buesseler, K., Livingston, H., Ivanov, L., and Romanov, A.: Stability of the oxic-anoxic interface in the Black Sea, Deep-Sea Res. Pt. I, 41, 283-296, 1994.

Capet, A., Barth, A., Beckers, J.-M., and Grégoire, M.: Interannual variability of Black Sea's hydrodynamics and connection to atmospheric patterns, Deep-Sea Res. Pt. II, 77-80, 128-142, doi:10.1016/j.dsr2.2012.04.010, 2012.

Capet, A., Beckers, J.-M., and Grégoire, M.: Drivers, mechanisms and long-term variability of seasonal hypoxia on the Black Sea northwestern shelf - is there any recovery after eutrophication?, Biogeosciences, 10, 3943-3962, doi:10.5194/bg-10-3943-2013, 2013.

Capet, A., Troupin, C., Carstensen, J., Grégoire, M., and Beckers, J.-M.: Untangling spatial and temporal trends in the variability of the Black Sea Cold Intermediate Layer and mixed Layer Depth using the DIVA detrending procedure, Ocean Dynam., 64, 315324, 2014.

Carval, T., Keeley, B., Takatsuki, Y., Yoshida, T., Stephen, L., Schmid, C., Goldsmith, R., Wong, A., McCreadie, R., Thresher, A., and Tran, A.: Argo User's manual, V3.2., doi:10.13155/29825, 2014.

Cleveland, W. S., Grosse, E., and Shyu, W. M.: Local regression models, in: Statistical models in S, edited by: Chambers, J. and Hastie, T., Wadsworth \& Brooks/Cole, 1992.

Codispoti, L., Friederich, G., Murray, J., and Sakamoto, C.: Chemical variability in the Black Sea: implications of continuous ver- tical profiles that penetrated the oxic/anoxic interface, Deep-Sea Res. Pt. I, 38, S691-S710, 1991.

Efimov, V., Stanichnyi, S., Shokurov, M., and Yarovaya, D.: Observations of a quasi-tropical cyclone over the Black Sea, Russ. Meteorol. Hydrol., 33, 233-239, 2008.

Glazer, B. T., Luther, G. W., Konovalov, S. K., Friederich, G. E., Trouwborst, R. E., and Romanov, A. S.: Spatial and temporal variability of the Black Sea suboxic zone, Deep-Sea Res. Pt. II, 53, 1756-1768, 2006.

Johnson, K. S., Plant, J. N., Riser, S. C., and Gilbert, D.: Air Oxygen Calibration of Oxygen Optodes on a Profiling Float Array, J. Atmos. Ocean. Tech., 32, 2160-2172, 2015.

Kempe, S., Liebezett, G., and Diercks, A.-R.: Water balance in the Black Sea, Nature, 346, p. 419, 1990.

Kideys, A. E.: Fall and rise of the Black Sea ecosystem, Science, 297, 1482-1484, 2002.

Konovalov, S., Murray, J. W., Luther, G., and Tebo, B.: Processes controlling the redox budget for the oxic/anoxic water column of the Black Sea, Deep-Sea Res. Pt. II, 53, 1817-1841, doi:10.1016/j.dsr2.2006.03.013, 2006.

Konovalov, S. K. and Murray, J. W.: Variations in the chemistry of the Black Sea on a time scale of decades (1960-1995), J. Marine Syst., 31, 217-243, 2001.

Konovalov, S. K., Luther III, G., Friederich, G. E., Nuzzio, D. B., Tebo, B. M., Murray, J. W., Oguz, T., Glazer, B., Trouwborst, R. E., Clement, B., Murray, K. J., and Romanov, A. S.: Lateral injection of oxygen with the Bosporus plume - fingers of oxidizing potential in the Black Sea, Limnol. Oceanogr., 48, 2369-2376, 2003.

Kroiss, H., Zessner, M., and Lampert, C.: daNUbs: lessons learned for nutrient management in the Danube Basin and its relation to Black Sea euthrophication, Chem. Ecol., 22, 347-357, 2006.

Kubryakov, A. and Stanichny, S.: Seasonal and interannual variability of the Black Sea eddies and its dependence on characteristics of the large-scale circulation, Deep-Sea Res. Pt. I, 97, 80-91, 2015.

Mee, L., Friedrich, J., and Gomoiu, M.-T.: Restoring the Black Sea in times of uncertainty, Oceanography, 18, 32-43, 2005.

Mee, L. D.: The Black Sea in crisis: a need for concerted international action, Ambio, 21, 278-86, 1992.

Murray, J., Jannasch, H., Honjo, S., Anderson, R., Reeburgh, W., Top, Z., Friederich, G., Codispoti, L., and Izdar, E.: Unexpected changes in the oxic/anoxic interface in the Black Sea, Nature, 338, 411-413, 1989.

Murray, J. W., Codispoti, L. A., and Friederich, G. E.: Oxidation/reduction environments, in: Aquatic Chemistry: Interfacial and Interspecies Processes, ACS Publications, 244, 157-176, 1995.

Oguz, T. (Ed.): State of the Environment of the Black Sea (20012006/7), Publications of the Commission on the Protection of the Black Sea Against Pollution (BSC), available at: http: //www.blacksea-commission.org/_publ-SOE2009.asp (last access: November 2015), 2008.

Oguz, T. and Cokacar, T.: Climatic warming and accompanying changes in the ecological regime of the Black Sea during 1990s, Global Biogeochem. Cy., 17, 1088, doi:10.1029/2003GB002031, 2003.

Oguz, T., Dippner, J. W., and Kaymaz, Z.: Climatic regulation of the Black Sea hydro-meteorological and ecological properties at 
interannual-to-decadal time scales, J. Marine Syst., 60, 235-254, doi:10.1016/j.jmarsys.2005.11.011, 2006.

Ostrovskii, A. and Zatsepin, A.: Short-term hydrophysical and biological variability over the northeastern Black Sea continental slope as inferred from multiparametric tethered profiler surveys, Ocean Dynam., 61, 797-806, 2011.

Öszoy, E. and Ünlüata, Ü.: Oceanography of the Black Sea: a review of some recent results, Earth-Sci. Rev., 42, 231-272, 1997.

Pakhomova, S., Vinogradova, E., Yakushev, E., Zatsepin, A., Shtereva, G., Chasovnikov, V., and Podymov, O.: Interannual variability of the Black Sea Proper oxygen and nutrients regime: The role of climatic and anthropogenic forcing, Estuarine, Coastal Shelf Science, 140, 134-145, 2014.

Piotukh, V., Zatsepin, A. G., Kazmin, A., and Yakubenko, V.: Impact of the Winter Cooling on the Variability of the Thermohaline Characteristics of the Active Layer in the Black Sea, Oceanology, 51, 221-230, 2011.

Saydam, C., Tugrul, S., Basturk, O., and Oguz, T.: Identification of the oxic/anoxic interface by isopycnal surfaces in the Black Sea, Deep-Sea Res. Pt. I, 40, 1405-1412, 1993.

Shaffer, G.: Phosphate pumps and shuttles in the Black Sea, Nature, 321, 515-517, 1986.

Stanev, E., Staneva, J., Bullister, J., and Murray, J. W.: Ventilation of the Black Sea pycnocline. Parameterization of convection, numerical simulations and validations against observed chlorofluorocarbon data, Deep-Sea Res. Pt. I, 51, 2137-2169, doi:10.1016/j.dsr.2004.07.018, 2004.

Stanev, E., He, Y., Grayek, S., and Boetius, A.: Oxygen dynamics in the Black Sea as seen by Argo profiling floats, Geophys. Res. Lett., 40, 3085-3090, 2013.

Stanev, E. V., He, Y., Staneva, J., and Yakushev, E.: Mixing in the Black Sea detected from the temporal and spatial variability of oxygen and sulfide - Argo float observations and numerical modelling, Biogeosciences, 11, 5707-5732, doi:10.5194/bg-115707-2014, 2014.
Staneva, J. and Stanev, E.: Water mass formation in the Black Sea during 1991-1995, J. Marine Syst., 32, 199-218, doi:10.1016/S0924-7963(02)00038-6, 2002.

Takeshita, Y., Martz, T. R., Johnson, K. S., Plant, J. N., Gilbert, D., Riser, S. C., Neill, C., and Tilbrook, B.: A climatology-based quality control procedure for profiling float oxygen data, J. Geophys. Res.-Oceans, 118, 5640-5650, 2013.

Troupin, C., Machín, F., Ouberdous, M., Sirjacobs, D., Barth, A., and Beckers, J.-M.: High-resolution climatology of the North-East Atlantic using Data-Interpolating Variational Analysis (DIVA), J. Geophys. Res., 115, C08005, doi:10.1029/2009JC005512, 2010.

Troupin, C., Sirjacobs, D., Rixen, M., Brasseur, P., Brankart, J.M., Barth, A., Alvera-Azcárate, A., Capet, A., Ouberdous, M., Lenartz, F., Toussaint, M.-E., and Beckers, J.-M.: Generation of analysis and consistent error fields using the Data Interpolating Variational Analysis (DIVA), Ocean Model., 52-53, 90-101, doi:10.1016/j.ocemod.2012.05.002, 2012.

Tugrul, S., Basturk, O., Saydam, C., and Yilmaz, A.: Changes in the hydrochemistry of the Black Sea inferred from water density profiles, Nature, 359, 137-139, 1992.

Tugrul, S., Murray, J. W., Friederich, G. E., and Salihoğlu, İ.: Spatial and temporal variability in the chemical properties of the oxic and suboxic layers of the Black Sea, J. Marine Syst., 135, 29-43, 2014.

Yakushev, E., Pollehne, F., Jost, G., Kuznetsov, I., Schneider, B., and Umlauf, L.: Analysis of the water column oxic/anoxic interface in the Black and Baltic seas with a numerical model, Mar. Chem., 107, 388-410, 2007.

Zatsepin, A., Golenko, N., Korzh, A., Kremenetskii, V., Paka, V., Poyarkov, S., and Stunzhas, P.: Influence of the dynamics of currents on the hydrophysical structure of the waters and the vertical exchange in the active layer of the Black Sea, Oceanology, 47, 301-312, 2007. 